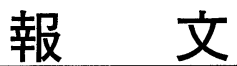

色材, 68〔5〕, 271-276（1995）

\title{
非イオン界面活性剂ミセル水溶液における 合成香料の可溶化平衡定数
}

\author{
近藤行 成 ${ }^{1)}$ - 水口勝 信 $^{1)}$ ・徳岡由- ${ }^{1) *}$ ・

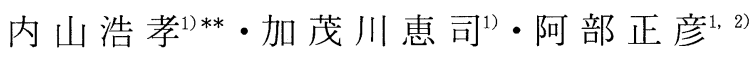

要 旨

ポリオキシエチレン (POE) 鎖長 (n) の異なる 4 種類の非イオン界面活性剤 \{ヘキサデシルポリオキシエチ レンエーテル $\left.\left(\mathrm{C}_{16} \mathrm{POEn} ; \mathrm{n}=10,20,30,40\right)\right\}$ を用いた合成香料 $\{2$-フェニルエチルアルコール $(\mathrm{PE}$ A), ベンジルアセテート (BA), d-リモネン $(\mathrm{LN})\}$ の可溶化を, 可溶化平衡定数およびミセル粒子径の測 定から検討した。香料の可溶化平衡定数は, 非イオン界面活性剤の POE 鎖長あるいは香料の HLB 值の増加に 伴い減少した。ミセル中における PEA の活量係数は他の香料よりかなり小さく, $0.1 \sim 0.2$ であった。また, 香料 1 分子を可溶化するのに必要な界面活性剤の分子数（ 2 B 值）は, LN の場合 $0.7 \sim 1.0$, BA の場合 $0.4 \sim$ 1. 0, PEA の場合 1.7 2.8 であった。さらに, $\mathrm{C}_{16} \mathrm{POE}_{10}$ ミセルの粒子径は PEA の可溶化量の増加に伴い増大 した。これらのことから, PEA は LN や BA に比べ, より強くミセル親水部の POE 鎖（親水基）に吸着し， POE 鎖の脱水和を誘起することが示唆された。

\section{1. 緒言}

非イオン界面活性剂は，イオン性界面活性剂に比べて 耐硬水性に優れ，イオン強度の高い水溶液中においでも 界面活性を示す両親媒性物質である。なかでも, 親水基 がポリオキシエチレン（POE）鎖から成る界面活性剂 は合成の段階で任意に親水基の長さを調節できるため, 使用目的に適合した HLB（親水性一疎水性バランス） 值が得られる特徵を有している1)。このため, POE 系 非イオン界面活性剤は洗浄剤, 分散剂, 乳化剤, 可溶化 剂として医薬品, 化粧品, 食品等に広く利用され ${ }^{2}$, そ

平成 6.11 .8 受理

1) 東京理科大学理工学部 （干278千葉県野田市山猗 2641）

2 ) 東京理科大学界面科学研究所 （干162 東京都新宿区神楽坂 1-3） *現勤務先 ; エステー化学(株)応用研究部 (干161 東京都新宿区下落合 1-4-10)

**現勤務先 ; プロクター・アンド・ギャンブル・ファー・ イースト・インク研究開発本部

（干658 兵庫県神戸市東灘区向洋町中 1-17）
の基礎研究も盛んになされてきている ${ }^{3 \sim 6)}$ 我々は, これまでに POE 系非イオン界面活性㓮であ るアルキルポリオキシエチレンエーテル (CmPOEn) を用いて合成香料の最大添加量（最大可溶化量）を測定 し, ミセル内での合成香料の可溶化位置, 最大添加量に 及ぼす POE 鎖長の影響等について検討した7)。しか し, 可溶化溶液の実使用に際しては, 被可溶化物濃度が 最大添加量であることは少ないため, 被可溶化物のバル クーミセル間の分配や溶存状態などに関する知見は十分 とはいえない。

そこで本研究では, POE 鎖長の異なる 4 種類のへキ サデシルポリオキシエチレンエーテル $\left(\mathrm{C}_{16} \mathrm{POEn} ; \mathrm{n}=\right.$ $10,20,30,40 ）$ を用いて合成香料を可溶化させ, 最大 添加量以下における香料の可溶化平衡定数および可溶化 したミセルの粒子径の測定を行い，可溶化平衡に及ぼす POE 鎖長の影響ならびに可溶化機構について検討し た。 
Table 1 Chemical structure and purity of synthetic perfumes

\begin{tabular}{|c|c|c|}
\hline synthetic perfumes & Chemical structure & Purity \\
\hline $\begin{array}{c}\text { 2-Phenylethyl alcohol } \\
\text { (PEA) }\end{array}$ & $\mathrm{H}_{2} \mathrm{OH}$ & $>98 \%$ \\
\hline $\begin{array}{c}\text { Benzyl acetate } \\
\text { (BA) }\end{array}$ & 3 & $>98 \%$ \\
\hline $\begin{array}{l}\text { d-Limonene } \\
\text { (LN) }\end{array}$ & & $>9$ \\
\hline
\end{tabular}

\section{2. 実験}

\section{1 試料}

2.1 .1 非イオン界面活性剂

非イオン界面活性剤であるへキサデシルポリオキシエ チレンエーテル $\left(\mathrm{C}_{16} \mathrm{H}_{33} \mathrm{O}\left(\mathrm{C}_{2} \mathrm{H}_{4} \mathrm{O}\right) \mathrm{nH} ; \mathrm{C}_{16} \mathrm{POEn}\right)$

は, 日本サーファクタント(株より提供されたもので, エ チレンオキシド付加モル数 $(\mathrm{n})$ が $10,20,30,40$ の ものを用いた。これらはいずれも比較的分子量分布が小 さいものである。またここれらの界面活性剤の純度は示 差走査熱量測定および表面張力測定により，純度 99.9 \%以上であることを確認した。

\subsection{2 合成香料}

2-フェニルエチルアルコール (PEA) は東京化成(株) 製の特級品を, ベンジルアセテート（BA）並びに d-リ モネン（LN）は長谷川香料(株)より購入したものをその まま試料に供した。香料の構造式，分子量並びに純度を 表-1 に示す。

\section{1.3 水}

水は大塚製薬(株)製の日本薬局方注射用水（注射用蒸留 水）を用いた。

\section{2 実験方法}

\subsection{1 可溶化溶液の調製}

$100 \mathrm{~mL}$ のサンプルびんに $0.050 \mathrm{~mol} / \mathrm{L}$ の非イオン界 面活性剤水溶液を採取し, それぞれに所定量の香料を添 加した。これらの水溶液を $30^{\circ} \mathrm{C}$ 恒温下で 12 時間攪拌 した後, 12 時間静置して香料を可溶化平衡に到達さ せ, 可溶化溶液とした。

\section{2 .2 可溶化平衡定数の測定}

可溶化平衡定数は準平衡透析（SED） 法 ${ }^{8)}$ ，9)により 測定した。すなわち, 分子量 6,000 ダルトン以上の分子 をカットするセルロース膜（セルロースアセテート製） を透析セル (Sanplatec Co. 製) にセットする。その
一方（原液側； retentate）に可溶化溶液を採取し，他 方（透析側； permeate）には純水を採取して, $30^{\circ} \mathrm{C}$ 恒温下にて 24 時間透析した後, 透析側の界面活性剂濃 度並びに香料濃度を定量し，前報に準じて ${ }^{8 \sim 10)}$ 可溶化 平衡定数 $\mathrm{K}$ を算出した。

本研究において, 可溶化平衡定数 $\mathrm{K}\left(\mathrm{M}^{-1}\right)$ は次式よ り求めた。

$$
\mathrm{K}=\frac{\mathrm{X}}{\mathrm{C}}=\frac{\mathrm{X}}{55.5 \cdot \mathrm{X}_{\text {bulk }}}
$$

ここで, X はミセル中における被可溶化物（合成香 料) のモル分率（X=[ミセル中の香料濃度 $] /([$ ミ ルを形成する界面活性剂濃度］＋［ミセル中の香料濃 度])), C は可溶化されずにバルク相中に存在する香料 の濃度 (M) であり, X bulk はバルク相中に存在する香 料のモル分率である。

\subsection{3 $\mathrm{C}_{16} \mathrm{POEn}$ 並びに合成香料の定量}

$\mathrm{C}_{16} \mathrm{POEn}$ の定量は, SED 実験終了後, 透析セルから 採取した試料溶液中に溶存する有機炭素量を全有機炭素 計（島津製作所(株)製；TOC-5000）を用いて測定し，こ の炭素量を $\mathrm{C}_{16}$ POEn 濃度に換算することにより行っ た。また, 香料は分光光度計（島津製作所(森製；MPS2000）を用い，試料溶液の吸光度を測定することにより 定量した。

\section{2.4 ミセルの粒子径測定}

ミセルの粒子径測定は, 光源として Ar イオンレー ザー（Coherent 社製；Innova 90）を取り付けた動的 光散乱装置（Malvern 社製; System 4700）を用い散 乱角 $90^{\circ}, 30^{\circ} \mathrm{C}$ 恒温下にて行った。

\section{3. 結果および考察}

可溶化平衡定数 $\mathrm{K}$ とミセル中における被可溶化物の モル分率 Xとの間には, 多くの可溶化系に対して次式 が成立することが実験的に知られている8 11)。

$$
\sqrt{\mathrm{K}}=\sqrt{\mathrm{K}_{0}}-\mathrm{B} \sqrt{\mathrm{K}_{0}} \mathrm{X}
$$

なお， $\sqrt{\mathrm{K}}$ は可溶化平衡定数の平方根值, $\mathrm{K}_{0}$ は $\mathrm{X} \rightarrow$ 0 における可溶化平衡定数，B は定数である。

そこで本研究でも, 可溶化平衡定数を（2）式により 検討することにした。その結果, 後述するように, いず れの可溶化系においても $\sqrt{\mathrm{K}}$ 值は X の増加に伴いほぼ 直線的に変化し,（2）式の関係が成立することを確認 した。

\section{1 可溶化平衡に及ぼすミセル内香料のモル分率の 影響}




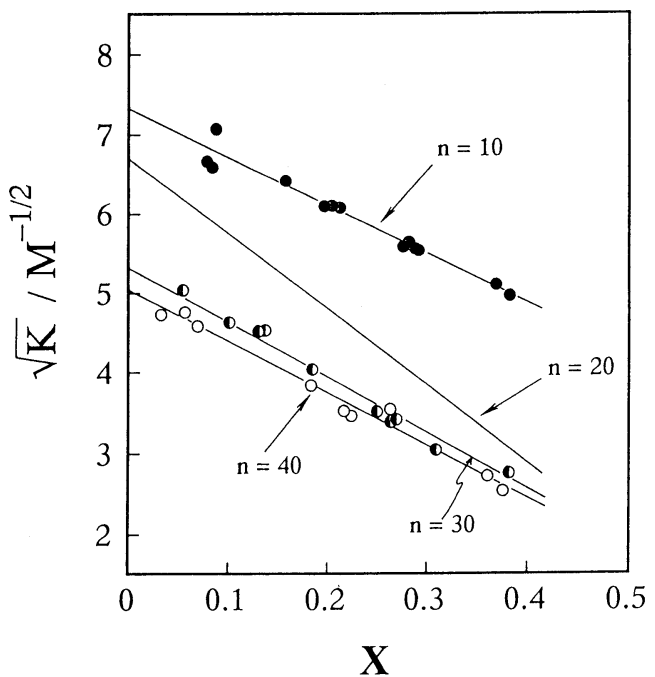

Fig. 1 Dependence of solubilization equilibrium constants for $\mathrm{PEA}$ in $\mathrm{C}_{16} \mathrm{POEn}$ micelles on the intramicellar mole fraction of synthetic perfume $\sqrt{\mathrm{K}}-\mathrm{X}$ line for the $\mathrm{C}_{16} \mathrm{POE}_{20} \mathrm{mi}$ celle-PEA ; from ref. 8 .

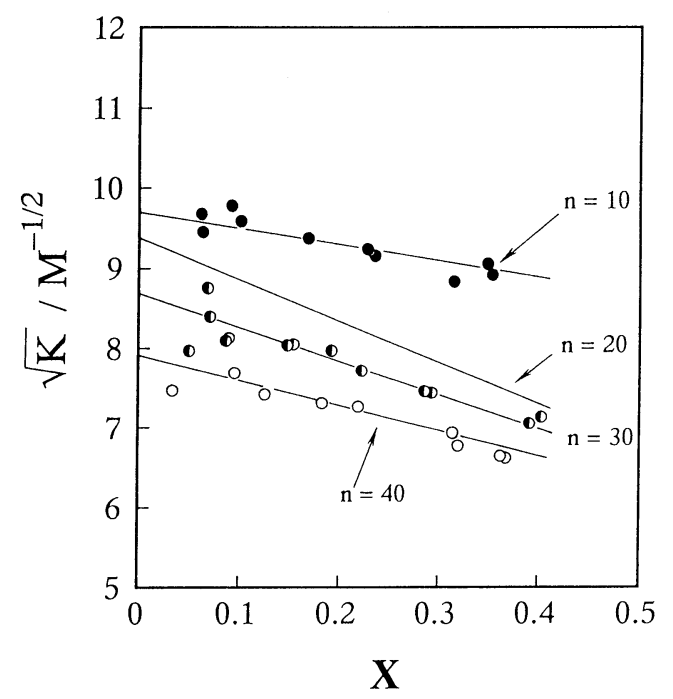

Fig. 2 Dependence of solubilization equilibrium constants for $\mathrm{BA}$ in $\mathrm{C}_{16} \mathrm{POEn}$ micelles on the intramicellar mole fraction of synthetic perfume

$\sqrt{\mathrm{K}}-\mathrm{X}$ line for the $\mathrm{C}_{16} \mathrm{POE}_{20} \mathrm{mi}$ celle-BA ; from ref. 8 .

$\mathrm{C}_{16}$ POEn-PEA 系, $\mathrm{C}_{16}$ POEn-BA 系, $\mathrm{C}_{16}$

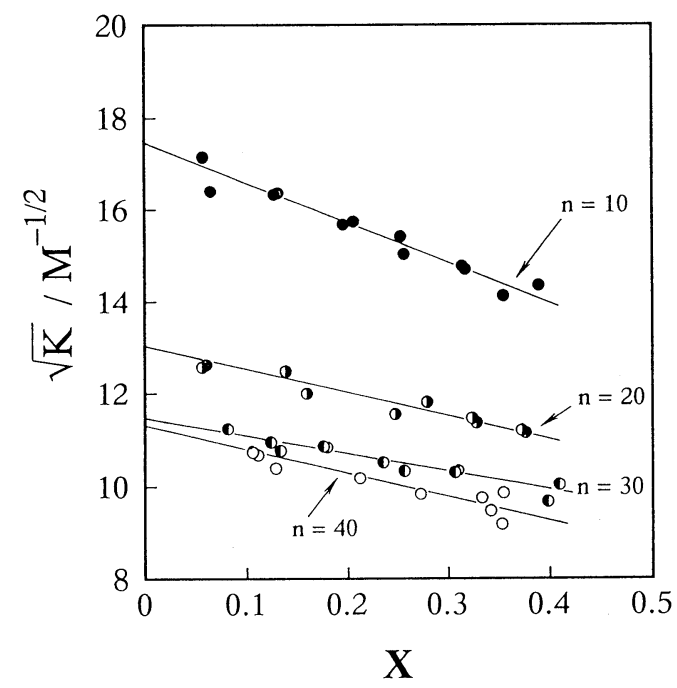

Fig. 3 Dependence of solubilization equilibrium constants for $\mathrm{LN}$ in $\mathrm{C}_{16} \mathrm{POEn}$ micelles on the intramicellar mole fraction of synthetic perfume

POEn-LN 系の可溶化平衡定数の平方根值と $\mathrm{X}$ との関 係を図-1〜3 に示す。

いずれの香料を用いた場合も, $\sqrt{\mathrm{K}}$ 值は X の増加に 伴い減少した。これはミセル内における香料のモル分率 が高くなると, 可溶化平衡定数が小さくなることを意味 する。

界面活性剂水溶液中における可溶化平衡は, 被可溶化 物と界面活性剤との親和性に依存すると考えられる。ま た, ミセル内における香料のモル分率が増加するとミセ ル内部の香料は純液体状態に近づくと考えられる。つま り, ミセル内における香料のモル分率の増加（X の増 加）に伴いミセル内における香料と界面活性剂との親和 性が低下するため K 值が減少したものと考えられる。

\section{2 可溶化平衡に及ぼすポリオキシェチレン （POE）鎖長の影響}

図-1〜3 から明らかなように, $\sqrt{\mathrm{K}}$ 值は $\mathrm{n}$ の増加に伴 い低下し, 界面活性剤の POE 鎖が長いほど香料は可溶 化され難いことが分かった。

$\mathrm{C}_{16} \mathrm{POEn}$ ミセル中に可溶化された香料の $\mathrm{X} \rightarrow 0$ にお ける活量係数と POE 鎖長との関係を図-4に示す。な お，活量係数は次式を用いて計算した ${ }^{8 \sim 11) 。 ~}$

$$
\gamma=\frac{1}{\mathrm{KC}^{0}}=\frac{\mathrm{C}}{\mathrm{C}^{0} \mathrm{X}}
$$

（ $\mathrm{C}^{0}$ は香料の水への飽和溶解度） 


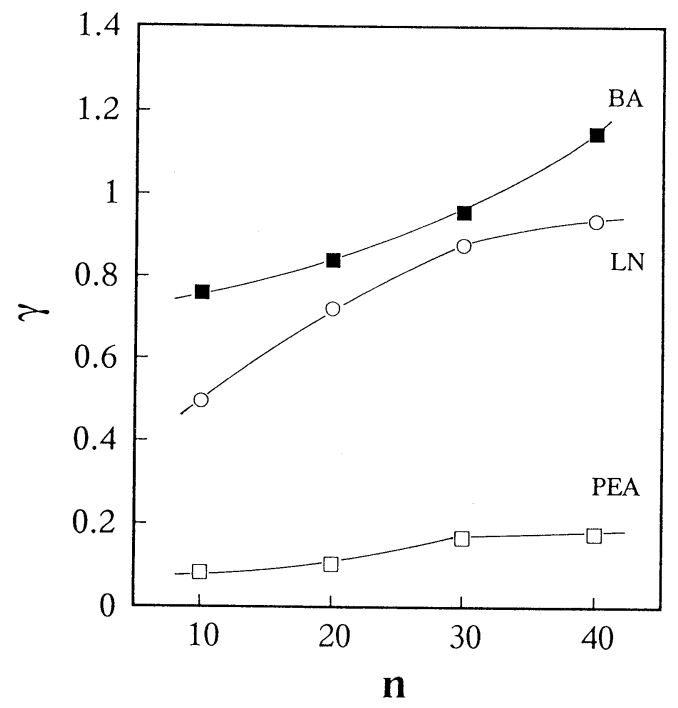

Fig. 4 Activity coefficients of synthetic perfumes in $\mathrm{C}_{16} \mathrm{POEn}$ micelles atX $\rightarrow 0$.

図から明らかなように，BA や LN を用いた場合の活 量係数は POE 鎖長の増加に伴いかなり増加したが, PEA を用いた場合にはほとんど依存しなかった（0.10.2)。なお，この傾向はどの X 值においても認められ た。

我々は先に, $\mathrm{C}_{16} \mathrm{POEn}$ の曇点に及ぼす合成香料の添 加効果および $\mathrm{C}_{16} \mathrm{POE}_{20} /$ ドデシル硫酸ナトリウム （SDS）混合系における香料の可溶化平衡定数を検討 し, 本研究で用いた 3 種類の香料は界面活性剂のエチレ ンオキシド部に可溶化すると報告した ${ }^{7)}$, 8)。したがっ て，図-4に見られる活量係数の変化は，POE 鎖の配向 状態, すなわち鎖の絡み合いの度合いにより, 香料の可 溶化状態が変化するために起こるものと思われる。ただ し, PEA の活量係数の変化は他の香料に比べ小さかっ たことから，PEA の可溶化位置近傍の POE 鎖の配向 状態は POE 鎖長にほとんど依存しないものと考えられ る。

\section{3 可溶化平衡定数に及ぼす合成香料のHLBの影響}

$\mathrm{X} \rightarrow 0$ における可溶化平衡定数 $\mathrm{K}_{0}$ と香料の HLB 值 との関係を表-2 に示す。なお, HLB 值は藤田の方法に 準じて ${ }^{12},{ }^{13)}$ 計算した。表から明らかなように， $\mathrm{K}_{0}$ 值は 香料の HLB 值の増加に伴い減少した。なお，この傾向 はごの X 值における可溶化平衡定数についても認めら れた。HLB 值が大きいほど, その物質の疎水性が低い ことから, 可溶化平衡定数は香料の疎水性が高いほど大
Table $2 \mathrm{~K}_{0}$ values for $\mathrm{C}_{16}$ POEn micelle-synthetic perfume systems

\begin{tabular}{cc|rrrr}
\hline \multirow{2}{*}{$\begin{array}{c}\text { Synthetic } \\
\text { perfume }\end{array}$} & HLB value & 10 & 20 & 30 & 40 \\
\cline { 3 - 6 } & \multicolumn{5}{|c}{$\mathrm{K}_{0} / \mathrm{M}^{-1}$} \\
\hline PEA & 7.2 & 53.5 & 44.6 & 28.1 & 25.3 \\
\hline BA & 4.2 & 93.9 & 86.1 & 75.5 & 62.4 \\
\hline LN & 0.8 & 305.3 & 169.8 & 131.7 & 127.8 \\
\hline
\end{tabular}

Table 3 Parameters $\mathrm{B}$ and $2 \mathrm{~B}$ for the $\mathrm{C}_{16}$ POEn micelle-synthetic perfume systems

\begin{tabular}{|c|c|c|c|c|c|c|}
\hline \multirow{2}{*}{$\begin{array}{c}\text { POE lenght } \\
n\end{array}$} & \multicolumn{2}{|c|}{ PEA } & \multicolumn{2}{|c|}{$\mathrm{BA}$} & \multicolumn{2}{|c|}{$\mathrm{LN}$} \\
\hline & B & $2 \mathrm{~B}$ & B & $2 \mathrm{~B}$ & B & $2 \mathrm{~B}$ \\
\hline 10 & 0.83 & 1. 67 & 0.21 & 0.41 & 0.50 & 1.00 \\
\hline 20 & 1. 41 & 2.82 & 0.44 & 0.88 & 0.39 & 0.77 \\
\hline 30 & 1. 29 & 2.58 & 0.49 & 0.99 & 0.33 & 0.67 \\
\hline 40 & 1. 28 & 2. 55 & 0.39 & 0.78 & 0.45 & 0.90 \\
\hline
\end{tabular}

きくなることが示唆された。

\section{4 合成香料の可溶化機構}

$\sqrt{\mathrm{K}}-\mathrm{X}$ 直線の傾きから得られた $\mathrm{B}$ 值とその倍数值 2 $\mathrm{B}$ を表-3 に示す。表から明らかなように，2 B 值は LN の場合 $0.7 \sim 1.0$, BA の場合 $0.4 \sim 1.0$, PEA の場 合 1.7 2.8である。Lee らは, ミセルによる油性物質 の可溶化をラングミュアー型の吸着と同じであると仮定 し，油性物質 1 分子を可溶化するのに要する界面活性剤 数は $2 \mathrm{~B}$ に等しくなることを報告している(0)。このこと から, $\mathrm{C}_{16} \mathrm{POEn}$ ミセル内において PEA 1 分子に約 2 〜 3 の界面活性剂分子が吸着するのに対し, BA や LN の場合には香料 1 分子にわずか 1 分子程度の界面活性剤 が吸着しているものと考えられる。

また，図-4で述べたように，PEA の活量係数は 0.1-0.2 であり，この值は LN および BA の活量係数よ りもかなり小さかった。活量係数が 1 以下の場合には, その值が小さいほど被可溶化物はミセル内で束縛されて いることを意味する。つまり，PEA 分子は LN 分子や BA 分子よりもミセル内でより束縛されている状態にあ ると考えられる。

さらに, 香料の可溶化状態について検討するため, PEA を可溶化したミセルの粒子径を測定した。 $\mathrm{C}_{16}$ POEn ミセルの粒子径とミセル水溶液中における PEA 


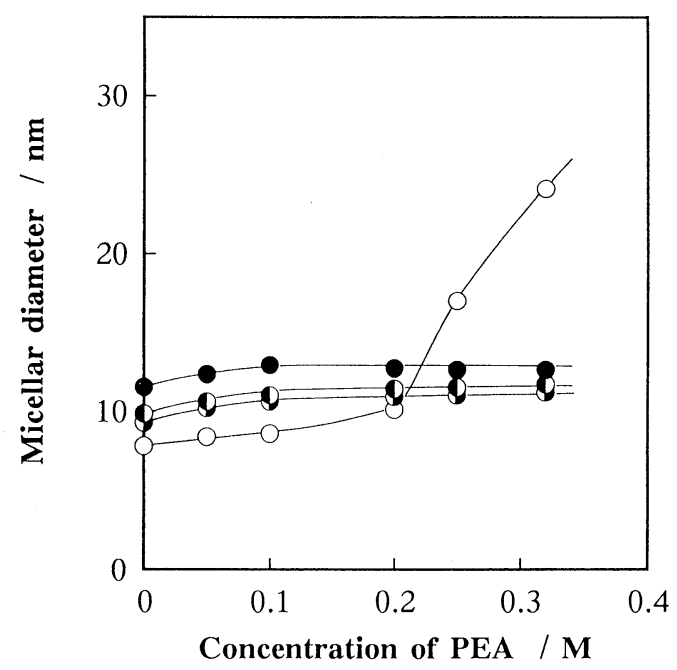

Fig. 5 Micellar diameter of $\mathrm{C}_{16}$ POEn as a function of the concentration of PEA.

$$
\begin{aligned}
& \bigcirc \mathrm{n}=10, \\
& ; \mathrm{n}=40
\end{aligned}
$$

濃度との関係を図-5に示す。図から明らかなように, n =20-40の場合, ミセルの粒子径は香料濃度に依存せず ほぼ一定の值を示したが, $\mathrm{n}=10$ の場合, その值はPEA 濃度が $0.2 \mathrm{M}$ 以上で急激に増大した。前報》において, $\mathrm{C}_{16} \mathrm{POEn}$ ミセルの粒子径は LN および BA の可溶化量 にはほとんど依存せず, 高い曇点低下能力を有する親水 性の高い香料を用いた場合のみその可溶化量に依存する ことを指摘し，これが POE 鎖の脱水和に起因すること を報告した。

以上のことから， PEA はその親水基である $\mathrm{OH}$ 基と 非イオン界面活性剤の POE 鎖間の水素結合により, LN や BA に比べて POE 鎖により強く吸着し, その結 果 $\mathrm{POE}$ 鎖の脱水和を誘起するものと考えられる。

\section{4. 結論}

POE 鎖長（n）の異なる 4 種類の非イオン界面活性
剂 $\mathrm{C}_{16} \mathrm{POEn}(\mathrm{n}=10,20 ， 30 ， 40 ）$ を用いた合成香料 (PEA，BA，LN）の可溶化を, 可溶化平衡定数並び にミセル粒子径の測定から検討した結果, 香料の可溶化 平衡定数は界面活性剂の POE 鎖長あるいは香料の HLB 值の増加に伴い減少することが分かった。また, 3 種類の香料の中で最も親水性の高い PEA は LN や BA に比べて POE 鎖により強く吸着し, 界面活性剂親 水基の脱水和を誘起することが考えられる。

\section{参 考 文 献}

1）中川俊夫 : 化学と工業, 14, 1135 (1961).

2）小田良平，寺村一広：“界面活性剤の合成とその 応用”, p.179, 槙書店 (1957).

3) T. Kuwamura, H. Takahashi : Bull. Chem. Soc. Jpn., 45, 617 (1972).

4) T. Nakagawa, K. Kuriyama, H. Inoue : $J$. Colloid Sci., 15, 268 (1960)

5) M. Abe, H. Uchiyama, T. Yamaguchi, T. Suzuki, K. Ogino, J. F. Scamehorn, S. D. Christian : Langmuir, 8, 2147 (1992).

6) Y. Tokuoka, H. Uchiyama, M. Abe : Colloid Polym. Sci., 272, 317 (1993).

7) Y. Tokuoka, H. Uchiyama, M. Abe, K. Ogino : J. Colloid Interface Sci., 152, 402 (1992).

8) M. Abe, K. Mizuguchi, Y. Kondo, K. Ogino, H. Uchiyama, J. F. Scamehorn, E. E. Tucker, S. D. Christian : J. Colloid Interface Sci., 160, 16 (1993).

9) Y. Kondo, M. Abe, K. Ogino, H. Uchiyama, J. F. Scamehorn, E. E. Tucker, S. D. Christian : Langmuir, 9, 899 (1993).

10) H. Uchiyama, S. D. Christian, J. F. Scamehorn, M. Abe, K. Ogino : Langmuir, 7, 95 (1991).

11) B. H. Lee, S. D. Christian, E. E. Tucker, J. F. Scamehorn : Langmuir, 6, 230 (1990).

12）藤田穆：“系統的有機定性分析” (純物質編), p. 61, 共立出版 (1953).

13）藤田穆 : 化学の領域, 11, 719 (1957). 


\title{
Solubilization Equilibrium Constants of Synthetic Perfumes in the Micellar Solutions of Nonionic Surfactants
}

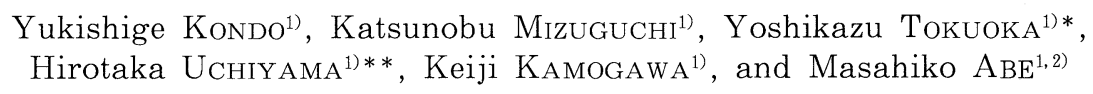

1) Fuculty of Science and Technology, Science University of Tokyo

(2641 Yamazaki, Noda-shi, Chiba 278)

2 ) Institute of Colloid and Interface Science, Science University of Tokyo

(1-3 Kagurazaka, Shinjuku-ku, Tokyo 162)

* Current address ; Research Department, S. T. Chemical Co., Ltd.

(4-10, 1-chome, Shimo-ochiai, Shinjuku-ku, Tokyo 161)

** Current address ; Research and Development Department, Procter \& Gamble Far East Inc.

(17, Koyo-cho Naka 1-chome, Higashinada-ku, Kobe, Hyogo 658)

\begin{abstract}
The solubilization of synthetic perfumecompounds $\{2$-phenylethyl alcohol (PEA), benzyl acetate (BA), d-limonene (LN)\} by four kinds of nonionic surfactant hexadecylpolyoxyethylene ether $\left.\left(\mathrm{C}_{16} \mathrm{POEn} ; \mathrm{n}=10,20,30,40\right)\right\}$ was investigated in terms of the measurements of solubilization equilibrium constants and micellar diameter. The solubilization equilibrium constants of the perfume compounds decrease with POE chain length of the surfactants and/or the HLB number of the perfume compounds. The activity coefficient of PEA in $\mathrm{C}_{16} \mathrm{POEn}$ micelles is appre ciably smaller than those of the other perfumes and is 0.1-0.2. The number of the surfactant required to solubilize one perfume molecule (parameter 2B) is ; for LN, 0.7-1.0, for BA, 0.4-1.0 for PEA, 1.7-2.8. Furthermore, the diameter of $\mathrm{C}_{16} \mathrm{POEn}$ micelles increases with increasing amount of the solubilized PEA. These results show that PEA molecule would adsorb more strongly to the POE chains in the micellar hydrophilic region than LN and BA molecules, resulting in the dehydration of the POE chains.
\end{abstract}

Key-words; Solubilization, Solubilization equilibrium constant, Nonionic surfactant, Perfume compound 